\title{
Estado da Arte em educação matemática na EJA: percursos de uma investigação
}

\author{
State of the art in mathematics teaching \\ in youth and adults education: paths of research
}

Adriano Vargas Freitas ${ }^{1}$. Célia Maria Carolino Pires ${ }^{2}$

\begin{abstract}
Resumo: Este artigo tem como objetivo promover reflexões a respeito de desafios, escolhas e possíveis soluções que envolvem o Estado da Arte, como modelo de pesquisa que visa promover um panorama sobre um determinado tema, em um determinado recorte de tempo. É parte de nosso doutorado realizado no âmbito de um projeto de pesquisa sobre Educação Matemática na Educação de Jovens e Adultos. Apresentamos informações sobre a nossa pesquisa e propomos algumas reflexões a respeito da necessidade de ampliarmos a forma conceitual e metodológica dessa modalidade de pesquisa. Apresentamos, também, a possibilidade de análise dos textos por meio da utilização da Análise Textual Discursiva, e, por fim, uma breve síntese de alguns dados coletados em nossa pesquisa.
\end{abstract}

Palavras-chave: Educação matemática. Estado da Arte. Educação de jovens e adultos. Análise do discurso.

\begin{abstract}
This article aims to promote reflections on challenges, choices and possible solutions involving the State of the Art, as a model of research that aims to promote an overview of a particular topic in a particular time frame. It is part of our doctoral studies within a research project on Mathematics Education in Youth and Adults. We provide information about our research and propose some reflections about the need to broaden the conceptual and methodology of this type of research. Here also the possibility of analyzing the text by using the Text Analysis Discourse and, finally, a brief summary of some data collected in our study.
\end{abstract}

Keywords: Mathematics education. State of the art. Education for youth and adults. Discourse analysis.

\footnotetext{
${ }^{1}$ Departamento de Educação, Instituto de Educação de Angra dos Reis (IEAR), Universidade Federal Fluminense (UFF), Avenida do Trabalhador, 179, CEP: 23914-290, Angra dos Reis, RJ, Brasil. Email: <adrianovargas@id.uff.br> ${ }^{2}$ Departamento de Matemática, Programa de Pós-Graduação em Educação Matemática, Universidade Federal de Mato Grosso do Sul (UFMS), Campo Grande, MS, Brasil.
} 


\section{Introdução}

Ao participarmos das discussões do Grupo de Pesquisa "Desenvolvimento Curricular em Matemática e Formação e Professores”, do Programa de Estudos Pós-Graduados em Educação Matemática da Pontifícia Universidade Católica de São Paulo (PUC-SP), percebemos que o campo de estudos relacionados à Educação Matemática voltada para a Educação de Jovens e Adultos (EJA) encontrava-se, ainda, bastante disperso e carente de maior atenção. Em meio a uma série de leituras e debates, foram sendo ressaltadas, pelo Grupo, a necessidade e vontade de investigarmos as produções dessa área, buscando conhecer quais a contribuições, conclusões e questões em aberto que elas têm nos apresentado nos últimos anos. Organizou-se, então, o projeto "Currículo de Matemática na Educação de Jovens e Adultos: dos intervenientes à prática em sala de aula", incluindo pesquisas de doutorado e mestrado sobre o tema. É nesse contexto que surge a estruturação básica de nossa pesquisa, que buscou apresentar o Estado da Arte da Educação Matemática na EJA sobre as pesquisas publicadas em periódicos constantes da listagem Qualis ${ }^{3}$ (da Coordenação de Aperfeiçoamento de Pessoal de Nível Superior - Capes), na área de Ensino de Ciências e Matemática, no período compreendido entre 2000 a 2010.

Nossa intenção foi buscar desvelar quanto os pesquisadores da área já caminharam, mas, também, investigar fragilidades que envolvem a Educação Matemática na EJA e vislumbrar caminhos que ainda precisam ser percorridos.

Os resultados obtidos neste projeto de pesquisa têm originado artigos e relatos em congressos. Entretanto, verificamos que, além de socializarmos esses resultados, seria interessante, também, divulgarmos o próprio processo de construção da pesquisa, visto que a viabilização de um Estado da Arte ainda se reveste de diversos percalços de que os antigos manuais de metodologia de pesquisa não têm dado conta. Em especial, pela quase impossibilidade de cobrir as diferentes estruturas e formas de elaboração dessa pesquisa.

A opção por trabalharmos com a produção que envolve a Educação Matemática voltada para a EJA, publicada no período de 2000 a 2010, em periódicos que façam parte da Listagem Qualis, foi feita em função de buscarmos privilegiar a produção teórica que, por sua natureza, foi legitimada por bancas compostas por especialistas pertencentes aos quadros de avaliadores dos periódicos, e que acabam por representar uma ampla e confiável fonte de dados a respeito do andamento e das conclusões de pesquisas; e, por muitas vezes, do caráter inconcluso da relação ensino/aprendizagem, que, por suas especificidades e sua polissemia, requerem dos pesquisadores uma ampla visão e cobertura sobre os fenômenos e diversas vozes que a envolvem.

O sentimento que nos moveu a optarmos por um trabalho do tipo Estado da Arte, foi o de buscar conhecer o já construído sobre Educação Matemática direcionada à EJA, para, a partir desse conhecimento, analisar: possíveis pontos de convergência e divergência, lacunas, consequências sociais e políticas, contribuições, divergências, generalizações e perspectivas para os futuros tempos.

\footnotetext{
${ }^{3}$ A Lista Qualis de periódicos é um conjunto de procedimentos utilizados pela CAPES para a estratificação da qualidade da produção intelectual dos programas de pós-graduação. A classificação é realizada pelas áreas de avaliação que enquadra as publicações em extratos indicativos de qualidade, podendo o mesmo periódico ser classificado de forma diferenciada em duas ou mais áreas distintas, o que expressaria o valor atribuído, em cada área, à pertinência do conteúdo veiculado.
} 
Do ponto de vista da relevância social e acadêmica, buscamos, em nosso estudo, a construção de material que possa referenciar discussões sobre o tema, reflexões e, também, o redimensionamento teórico-prático de projetos político-pedagógicos relacionados à EJA e, em especial, à área de Matemática, na busca de responder a questão: O que tem sido produzido e publicado sobre a Educação Matemática orientada para a Educação de Jovens e Adultos?

\section{As pesquisas no modelo de Estado da Arte}

O trabalho de analisar e discutir a produção acadêmica de uma determinada área do conhecimento num dado período é um desafio tomado por pesquisadores e grupos de pesquisa que, movidos pela percepção do não-conhecimento acerca da totalidade da produção dessa área, se aventuram a catalogar as suas diferentes dimensões e aspectos por meio do rastreamento de pesquisas, publicações, ou outras formas.

Em geral, faz parte dos estudos acadêmicos, apresentando-se de forma introdutória e resumida, mas algumas pesquisas tomam esse mapeamento reflexivo como sua metodologia e foco exclusivos. Nesses casos, o problema de pesquisa refere-se, diretamente, ao buscar cobrir uma gama de fenômenos de forma muito mais ampla do que aqueles que o pesquisador poderia conhecer diretamente, sendo possível, dessa forma, ter contato com a produção desenvolvida nos diversos centros universitários e extrauniversitários, nas diferentes regiões que compõem o vasto território de nosso país e, até mesmo, fora dele.

As pesquisas desenvolvidas sob esses aspectos são denominadas, em geral, de "Estado da Arte" ou "Estado do Conhecimento", por se tratar "de um instrumento que busca a compreensão do conhecimento sobre determinado tema, em um período de tempo específico e, consequentemente, sua sistematização e análise" (TEIXEIRA, 2006, p. 60). Mas podem receber outras denominações, tais como: "Síntese integrativa" (ANDRÉ, 2002), "Trabalhos inventariantes" (SOARES; MACIEL, 2000) ou "Pesquisas que estudam pesquisas" (SLONGO, 2004).

Laranjeira (2003) nos adverte que a expressão rebuscada "Estado da Arte" é ainda pouco compreendida em nosso país, tendo-nos sido impingida como uma cópia de uma denominação de uma modalidade de pesquisa estruturada no meio acadêmico dos Estados Unidos (state of the art), que visa diagnosticar algo ou uma determinada área de conhecimento. Significaria trazer a público indicativos de mapeamento de questões problemáticas da realidade concreta, seja para a demonstração de sua importância, seja para a percepção do pouco caso que lhe fazem.Para D’Ambrosio (1993), o Estado da Arte é equivalente a um trabalho de uma “Comissão de Programa de Congresso", que procura analisar, na literatura, os pontos que têm recebido maior atenção dos pesquisadores da área e que, portanto, têm sido seus maiores propulsores. Luna (2007, p. 82) descreve o objetivo de pesquisadores que optam por trabalhos elaborados sob a metodologia do Estado da Arte como uma busca para conhecer "o que já se sabe, quais as principais lacunas, onde se encontram os principais entraves teóricos e/ou metodológicos”. Destaca, dentre as muitas razões que revestem esses estudos de grande importância, o fato de que constituem excelente fonte de atualização para pesquisadores fora da área na qual se realiza o estudo, pelo fato de apresentarem condensamento dos pontos importantes do problema em questão.

A percepção da ampliação de enfoques e perspectivas sob os quais um determinado fenômeno é estudado requer um amplo inventário da produção acadêmica e científica, para que, 
à luz de categorias e/ou temas previamente selecionados, o pesquisador possa identificar, em cada uma das produções, ou no conjunto delas, as diferentes vertentes utilizadas para analisar o fenômeno. Soares e Maciel (2000, p. 3) justificam a relevância de trabalhos inventariantes da seguinte forma:

Essa compreensão do estado do conhecimento sobre um tema, em determinado momento, é necessária no processo de evolução da ciência, a fim de que se ordene periodicamente o conjunto de informações e resultados já obtidos, ordenação que permita a indicação das possibilidades de integração de diferentes perspectivas, aparentemente autônomas, a identificação de duplicações ou contradições e a determinação de lacunas ou vieses.

Essas possibilidades de contribuição com a organização e análise na definição de um campo ou uma área, são destacadas, também, nos estudos de Romanowski e Ens (2006), que analisam a importância de pesquisas desse tipo em nossa contemporaneidade marcada por intensas mudanças associadas aos avanços crescentes da ciência e da tecnologia.

Nessa perspectiva, o Estado da Arte pode significar importante contribuição na constituição do campo teórico de uma área do conhecimento, pois, além de identificar os aportes significativos da construção da teoria e prática pedagógica, podem apontar as restrições sobre o campo em que se move a pesquisa e as experiências inovadoras como alternativas para solução de problemas.

Tais análises possibilitam: o exame das ênfases e tendências aos temas abordados nas pesquisas de uma área, seus principais referenciais teóricos que subsidiaram as investigações, a relação entre o pesquisador e a prática pedagógica, as contribuições dessas pesquisas para mudanças e inovações dessas práticas pedagógicas, assim como suas limitações e possíveis conclusões.

De acordo com Haddad (2000, p. 4), os estudos do tipo Estado da Arte permitem, ao pesquisador, sistematizar um determinado campo de conhecimento, além de "identificar temáticas e abordagens dominantes e emergentes, bem como campos inexplorados abertos à pesquisa futura". Com base nesses pressupostos, este autor coordenou e publicou, em 2000, a pesquisa "Educação de Jovens e Adultos no Brasil (1986-1998)". Tal pesquisa faz parte de um conjunto de uma série organizada pelo Instituto Nacional de Estudos e Pesquisas Educacionais Anísio Teixeira (INEP), todas apresentando o Estado da Arte de determinada área da Educação. Dentre elas, destacamos: “Juventude e escolarização (1980-1998)" (SPOSITO, 2002); "Formação de professores no Brasil (1990-1998)" (ANDRÉ, 2002); "Políticas e gestão na educação (19911997)" (WITTMANN; GRACINDO, 2001), e "Educação superior em periódicos nacionais (1968-1995)" (MOROSINI, 2001).

Além da série de trabalhos elencados acima, poderíamos citar outros que têm despontado no cenário nacional e que se intitulam Estado da Arte. Como, por exemplo: "O Estado da Arte: a concepção de avaliação educacional veiculada na produção acadêmica do programa de pós-graduação em educação: currículo (1975-2000)" (TEIXEIRA, 2006), "Estado da Arte da área de educação \& comunicação em periódicos brasileiros" (VERMELHO; ABREU, 2005), e, ainda, a produção de D’Ambrosio (1993) “Educação Matemática: uma visão do estado da arte”. Consideramos que, com o perceptível avanço no desenvolvimento das novas tecno- 
logias e, em especial, a crescente difusão de informações propiciada pela internet, esse modelo de pesquisa tenha sido facilitado, visto que, cada vez mais, as universidades e outras entidades ligadas de alguma forma às pesquisas científicas estão optando por disponibilizar seus bancos de dados no ciberespaço. Essa sistematização de dados acaba por possibilitar, de forma significativa, que o pesquisador atue de forma mais abrangente, o que significa poder ampliar consideravelmente o universo a ser pesquisado, inclusive, em relação ao período e quantidade de publicações. Dessa forma, a necessidade de grandes deslocamentos geográficos é suprimida para dar lugar ao contato quase imediato com os trabalhos oriundos de diversas regiões, com suas diferentes matizes, e distintos olhares sobre um determinado tema, e, ao mesmo tempo, agilizar o processo de análise de um número considerável deles.

Sob tais considerações, e buscando compreender as formas de Estado da Arte que têm sido desenvolvidas em nosso país, efetuamos uma busca, via internet, no Banco de Teses ${ }^{4}$ da Coordenação de Aperfeiçoamento de Pessoal de Nível Superior (CAPES), por meio das expressões de busca "estado da arte" e "estado do conhecimento", e contabilizamos um total de 1.260 produções, entre dissertações de mestrado e teses de doutorado, que apresentaram tais expressões em seus títulos, nas palavras-chave ou no resumo, no período compreendido entre 1987 a $2010^{5}$. A Tabela 1 nos apresenta informações provenientes dessa consulta.

Tabela 1. Resultado da consulta ao Banco de Teses da CAPES a respeito da quantidade de produções realizadas no período de 1987 a 2010, relativas ao "Estado da Arte" ou "Estado do Conhecimento"

\begin{tabular}{|c|c|c|c|c|}
\hline \multirow[b]{2}{*}{ Nível } & \multicolumn{2}{|c|}{ Expressão pesquisada } & \multirow{2}{*}{$\begin{array}{c}\text { Total de } \\
\text { pesquisas } \\
\text { encontradas }\end{array}$} & \multirow{2}{*}{$\begin{array}{l}\text { Total de pesquisas } \\
\text { relativas à área de } \\
\text { Educação }\end{array}$} \\
\hline & $\begin{array}{c}\text { Estado do } \\
\text { Conhecimento }\end{array}$ & $\begin{array}{l}\text { Estado } \\
\text { da Arte }\end{array}$ & & \\
\hline Doutorado & 27 & 307 & 334 & 10 \\
\hline Mestrado & 53 & 873 & 926 & 58 \\
\hline Total & & & 1.260 & 68 \\
\hline
\end{tabular}

Fonte: Banco de Teses CAPES (Disponível em: <http://capesdw.capes.gov.br/capesdw/Teses.do>. Acesso em 28 abr. 2012).

Importante destacar alguns pontos que nos proporcionam uma visão geral a respeito das produções destacadas na Tabela 1: (1) embora tenhamos encontrado quantidade significativa de produções (1.260), verificamos que somente cerca de 5\% (68) relacionam-se diretamente à área de Educação; (2) um número ainda mais reduzido foi encontrado ao selecionarmos as pesquisas relacionadas à Educação Matemática: 0,9\% (11), sendo todas dissertações de mestrado; (3) dentre o total de 1.260 produções encontradas, apenas 0,2\% (2 dissertações de Mestrado)

\footnotetext{
${ }^{4}$ Disponível em: <http://capesdw.capes.gov.br/capesdw/Teses.do>. Acesso em: 28 abr. 2012.

${ }^{5}$ Destacamos que, até abril de 2012, período em que finalizamos a coleta dos dados, a CAPES ainda não havia disponibilizado as produções de 2011 e 2012 em sua página na internet.
} 
eram relacionadas ao tema EJA, e não foram encontradas produções (dissertações ou teses) que apresentassem estudos envolvendo diretamente a Educação Matemática na EJA, que foi o foco de nosso estudo.

Podemos tomar esse quadro como um bom exemplo do alerta que alguns pesquisadores apresentam em suas produções a respeito do tema. A partir da verificação da grande utilidade das pesquisas do tipo Estado da Arte para o avanço das diferentes áreas do conhecimento, e mesmo tendo sido verificado um movimento de expansão acentuada de sua construção e propagação, ainda termos diversas áreas que carecem dessa atenção nas pesquisas que apontem o já elaborado, os enfoques e as lacunas existentes.

Essas considerações encontramos, por exemplo, na produção realizada por Melo (2006), que apresenta um Estado da Arte sobre as pesquisas em Educação Matemática, tendo por base análises sobre teses e dissertações. Para essa autora, sendo o conhecimento um estado em efervescência, com diversas transformações e mudanças, é importante a elaboração da revisão dos conhecimentos desenvolvidos para que se possa olhar o futuro a partir de traços e antecedentes imediatos do cenário atual da pesquisa. Entretanto, destaca que, apesar dessa relevância, ainda há poucos autores e pesquisadores que se dedicam à realização de pesquisas do tipo Estado da Arte e, menos ainda, aqueles que escrevem e teorizam sobre esse tipo de pesquisa.

Considerações próximas verificamos, também, no trabalho de Rocha e Salvi (2010), que, ao elaborarem um panorama atual sobre os trabalhos, a partir da seleção de artigos em periódicos de ensino de Ciências, relataram poucos estudos relativos ao tema - situação interpretada, por eles, como sendo um reflexo da falta de maiores investimentos em pesquisas teóricas que permitam reflexões mais profundas e uma melhor compreensão das muitas dimensões possíveis que o envolvem.

Acrescentamos, a essas considerações, a nossa verificação de que, em muitos casos, ocorre a junção do pouco investimento aliado à pouca atratividade que um determinado tema tem despertado nos pesquisadores e grupos de pesquisa, visto, muitas vezes, como sendo de menor importância, ou um desafio que envolverá grande esforço, sem que seus resultados recebam a mesma atenção que outros temas recebem. Este nos parece, ainda, ser o caso da EJA e, em especial, no interior da Educação Matemática.

\section{Mas, afinal, como elaborar um Estado da Arte?}

É verificável que o Estado da Arte possibilita a percepção de que os conhecimentos científicos não evoluem de uma forma linear e progressiva, e que comportam contradições, inflexões, e uma multiplicidade de entendimentos como expressão dos contextos históricos, culturais, sociais e políticos em que foram produzidos. Entretanto, parece-nos ainda envolto em um grande mistério, no que se refere ao seu formato, sua metodologia e análise, carecendo de que seus conceitos sejam revistos e ampliados, e que suas metodologias e formas de análise das informações obtidas sejam discutidas nos manuais que nos apresentam os métodos de pesquisa científica.

Com relação à sua forma e conceito, encontramos no artigo de Ferreira (2002, p. 258) - que, por sinal, é um dos mais citados nas pesquisas do tipo Estado da Arte - a informação de que essas pesquisas são "definidas como de caráter bibliográfico". Porém, ao analisarmos 
produções, como a organizada por Litto e Formiga $(2009)^{6}$, ou, ainda, a produção envolvendo método etnográfico de Garcia (2005) 7 , facilmente poderemos verificar que tal conceito tornou-se restrito demais, e já não abarca as diferentes possibilidades e formas de conhecimentos de um tema de estudo, que vão bem além da revisão bibliográfica ou catalográfica de conhecimentos.

Ao buscarmos, especificamente, a metodologia a ser desenvolvida em um Estado da Arte, entraremos em uma seara ainda mais complexa, tendo, de um lado, o silêncio dos antigos compêndios (BOGDAN; BIKLEN, 1991), ou indicações que se resumem, basicamente, ao formato introdutório utilizado nas pesquisas (CRESWELL, 2007), ou, ainda, poucas indicações que acenem para a possibilidade da pesquisa ser exclusiva no formato do Estado da Arte (GIL, 2008).

De uma forma geral, quando é apresentada nos manuais de pesquisa científica, prescrevem os seguintes passos: (i) definição dos descritores para direcionar as buscas das informações; (ii) localização dos bancos de pesquisas (artigos, teses, acervos etc.); (iii) estabelecimento de critérios para a seleção do material que comporá o corpus do estudo; (iv) coleta do material de pesquisa; (v) leitura das produções, com elaboração de sínteses preliminares; (vi) organização de relatórios envolvendo as sínteses e destacando tendências do tema abordado; e (vii) análise e elaboração das conclusões preliminares.

Mais uma vez, aqui, destacamos a fragilidade verificada em tais considerações, ao não levarem em conta as múltiplas possibilidades de construção do Estado da Arte, assim como os movimentos de avanços e retrocessos que compõem qualquer tipo de pesquisa qualitativa, durante todo o seu processo de construção, que, no caso dessa modalidade, nunca cessa.

A percepção do inacabamento de uma pesquisa Estado da Arte, por sinal, é uma das características apontadas em diversos estudos, tais como o de Uler (2010) e o de Teixeira (2006), de onde destacamos o trecho a seguir:

[...] as pesquisas sobre o Estado da Arte ou do Conhecimento estão sempre inconclusas, uma vez que não podem ser finitas (ter término), levando-se em consideração, principalmente, o movimento ininterrupto da ciência, que se vai construindo ao longo do tempo, privilegiando, ora um aspecto, ora outro, em constante movimento. E nesse interlúdio, os conceitos sofrem mutações, devido às intervenções do próprio conceito de campo e, consequentemente, dos autores nele inseridos. (TEIXEIRA, 2006, p. 63)

Assim como ocorreu em nosso estudo a respeito da elaboração do Estado da Arte da Educação Matemática direcionado para a EJA, as pesquisadoras Vermelho e Abreu (2005)

\footnotetext{
${ }^{6}$ A produção "Educação a distância: o estado da arte" apresenta artigos originais, escritos por professores que foram convidados a relatarem as diversas vertentes que envolvem o tema e suas experiências nessa modalidade de ensino.

${ }^{7}$ A produção "Trabalho docente, formação e profissionalização: o que nos revela o cotidiano do professor" apresenta argumentos dissertativos de uma abordagem do trabalho docente a partir dos elementos de construção da profissão do professor. Os dados etnográficos que compõem a obra foram coletados junto a um grupo de professores pertencentes à rede pública de ensino.
} 
se depararam, em sua pesquisa, com uma série de dúvidas e dificuldades relacionadas à metodologia envolvida na elaboração do Estado da Arte da área de Educação e Comunicação em periódicos nacionais, e que, após terem efetuado leituras em uma grande gama de trabalhos com objetivos semelhantes, verificaram que teriam de elaborar uma metodologia própria, em função das singularidades e dificuldades envolvidas na proposta e foco da pesquisa.

Se até esse ponto destacamos, no Estado da Arte, a necessidade de um conceito amplo que envolva suas diferentes roupagens, e analisamos a complexidade que envolve as questões metodológicas dessas diferentes elaborações (de onde se pode concluir que a prescrição de caminhos não pode ser tomada como método sem prévia análise crítica dos objetivos, possibilidades e limitações do tema a ser analisado), chegamos, enfim, a um dos pontos nevrálgicos mais sensíveis do tema: a análise dos dados colhidos na pesquisa.

Algumas das produções que selecionamos como nossa fonte de informações para a compreensão das possibilidades e limites do Estado da Arte optaram por apresentar suas análises dos dados apenas na forma descritiva (com ênfase em detalhes quantitativos), como, por exemplo, no estudo de Carvalho (2009) envolvendo as pesquisas em Educação de Jovens e Adultos na CAPES no período de1987 a 2006. Outras apresentaram sínteses integrativas do conhecimento sobre o tema, aliando dados quantitativos à busca por uma compreensão das questões emergentes das produções, como, por exemplo, no Estado da Arte da formação de professores no Brasil, de André et al. (1999).

Houve, ainda, produções que fizeram a opção de explorar os dados obtidos sob uma perspectiva teórica, como, por exemplo, no estudo sobre a avaliação da aprendizagem desenvolvido por Uler (2010), a partir da produção acadêmica proveniente dos programas de pós-graduação em educação. Analisamos que, nesse caso, a necessidade de seleção de diversos teóricos para o desenvolvimento da análise dos dados deveu-se à própria diversidade de que foram compostas as produções selecionadas, apresentando múltiplas visões de seus autores que, ao serem analisadas sob uma forma homogeneizante de uma única linha teórica, podem perder (ou deturpar) parte de suas ideias.

Outro exemplo da mesma situação podemos destacar no estudo de Teixeira (2008), que nos relata, em seu Estado da Arte do ensino de Biologia no Brasil, a utilização de um vasto referencial para a tarefa de analisar os dados colhidos nessa sua pesquisa: "a estrutura teórica que dará suporte ao trabalho de análise está baseada num conjunto de aportes teóricos disseminados por pesquisadores" (TEIXEIRA, 2008, p. 2).

Em nosso estudo, optamos por acompanhar o emergir, a partir das leituras dos artigos, dos referenciais teóricos provenientes das pesquisas que originaram os estudos que compuseram nosso campo de análise. Nessa verificação, encontramos um extenso e, por demais, abrangente quadro teórico de diferentes linhas e posicionamentos, com destaques para dois que sobressaíram com significativa frequência, tanto em artigos nacionais quanto internacionais. São eles: Paulo Freire, e sua defesa por uma educação libertadora; e Ubiratan D’Ambrosio, e seu Programa de Etnomatemática.

Dessa forma, compreendidas as ações implicadas no desafio de elaborar um Estado da Arte que envolva a análise crítica e a compreensão da relevância e da consistência do conhecimento produzido no campo da Educação Matemática relacionada à EJA, passamos a nos mover em direção a esses objetivos. 


\section{A construção de nosso Estado da Arte}

O sentimento que move um pesquisador a optar por um trabalho do tipo Estado da Arte, segundo Ferreira (2002), é justamente o desafio do conhecimento quantitativo e qualitativo das produções sobre um tema, e, dessa forma, promover o aprimoramento desses conhecimentos a respeito de um tema, ou de uma área de estudo.

Sob esta perspectiva, e sem desconsiderar a importância de outras fontes de dados (assim como de diversos outros períodos), focamos, em nosso estudo, a produção acadêmica publicada no período compreendido entre 2000 e 2010, em periódicos nacionais e internacionais pertencentes à Listagem Qualis, organizada pela CAPES, na área de Ensino de Ciências e Matemática.

Segundo Gil (2008, p. 62), os periódicos constituem, atualmente, o meio mais importante para a comunicação científica, e graças a eles é que "vem-se tornando possível a comunicação formal dos resultados de pesquisas originais e a manutenção do padrão de qualidade na investigação científica". Para Rocha e Salvi (2010), a opção por utilizar revistas científicas como fonte de pesquisa é uma forma otimizada de se ter contato com grande parte da produção teórica produzida atualmente, e que, por isso, as próprias revistas acabam se firmando como excelentes veículos de circulação mais rápidos e práticos entre pesquisadores, professores e especialistas das mais diversas áreas.

Iniciamos a primeira parte da coleta dos dados buscando delimitar os periódicos que iriam fazer parte de nossa coleta de dados. Após algumas considerações a respeito da amplitude desafiadora e representatividade dos periódicos, e, também, a respeito do fator tempo, elaboramos quatro indicações de delimitação de nossa análise: (a) seriam analisados os periódicos pertencentes à listagem Qualis, classificados por A1, A2, B1, B2, B3, B4 ou B5, sendo excluídos apenas os de classificação C; (b) o período analisado de publicações nesses periódicos se iniciaria em janeiro de 2000 e iria até dezembro de 2010; (c) seriam analisadas as edições dos periódicos que estivessem disponibilizadas de forma completa e gratuita no ambiente virtual da internet; (d) seriam descartados os periódicos que apresentassem foco de interesse distante da área de Educação e/ou Educação Matemática.

Com relação ao item (a), reiteramos que, apenas os periódicos com classificação igual a C (o menor extrato da lista Qualis, de peso zero), não fizeram parte de nossa análise. Com essa delimitação, chegamos ao número de 325 periódicos. Sobre o item (b), destacamos a necessidade de demarcação de datas limites, para início e fim de coleta de dados, nos trabalhos do tipo Estado da Arte (TEIXEIRA, 2008; ULER, 2010), devido ao caráter abrangente desse tipo de investigação. Como nos lembra Haddad (2002), a construção de uma pesquisa do tipo Estado da Arte deve ter, em seu desenho estrutural, a delimitação de um espaço temporal, para que, dessa forma, possamos acompanhar o movimento do conhecimento do tema selecionado, o que não significa ignorar a percepção de que essa delimitação não implica a negação da infinitude desta pesquisa. A opção pelo recorte indicado no item (c) deveu-se à própria necessidade de delimitações relacionadas ao processo de coleta de dados, assim como a busca pela "otimização da pesquisa" (FERREIRA, 2002, p. 2). Destacamos que, em relação ao item (d), optamos por tomar como regra, em nossa análise, a postura de, mesmo após verificarmos que o periódico tinha campo de estudo distante do nosso foco de interesse, analisar, por meio de palavras-chave e títulos dos artigos, a possibilidade de, nesse periódico, ter sido publicado, em qualquer de suas 
edições disponibilizadas, algum artigo que envolvesse direta ou indiretamente a Educação e/ ou a Educação Matemática em EJA. Após a aplicação das delimitações da pesquisa, reduzimos o total de periódicos previamente selecionados para 95.

Para o trabalho de busca e análise dos artigos provenientes desses periódicos, optamos por desenvolver um trabalho em que almejamos ter contato com cada uma das edições disponíveis, número a número. Nosso intuito foi o de aumentar a amplitude e validade da pesquisa e, por consequência, sua credibilidade. Embora tal opção tenha nos exigido tempo e desgaste físico maior, ela foi necessária, visto que diversas publicações não contam, ainda, com um sistema de busca eficiente, e, em alguns casos, mesmo possuindo um bom sistema de busca, não disponibilizam o resumo ou as palavras-chave de todos os artigos.

Com relação a essa (falta de) disponibilização de informações sobre as produções pertencentes aos periódicos, nossa percepção foi a de que algumas revistas eletrônicas, e, em especial, as nacionais, ainda estão se adequando às ferramentas possibilitadas pelas bibliotecas virtuais, e que, aos poucos, estão organizando, no espaço virtual, as edições de suas publicações, sendo que as mais antigas são apresentadas, muitas vezes, em arquivos que dificultam a consulta via sistemas de busca.

A forma de seleção inicial foi feita via leitura dos títulos dos artigos, palavras-chave e assunto (quando havia). Após essa leitura, caso restasse dúvidas se o artigo se encaixaria ou não na pesquisa, passávamos a analisar o resumo. Porém, nessa etapa, por inúmeras vezes, verificamos que a leitura dos resumos também não seria suficiente para compreendermos o foco de estudo, devido à forma truncada como foram redigidos.

Esse mesmo tipo de dificuldade encontramos relatada em diversas outras pesquisas do tipo Estado da Arte (CARVALHO, 2009; TEIXEIRA, 2006; ULER, 2010; entre outros). Nesses casos, adotávamos a leitura completa ou de partes do texto até que encontrássemos indicações de pertencimento, ou não, ao nosso tema de pesquisa.

Nos casos em que o artigo apresentava indicações de poder ser incluído em nossa seleção, era copiado e gravado em pastas virtuais identificadas com indicações relativas ao periódico de origem e especificações de volume, número e ano de publicação. Para a organização dessa etapa de coleta de informações, elaboramos uma ficha individual de apontamento e dados (GIL, 2008), contendo: nome da publicação, instituição mantenedora, endereço na internet, idioma predominante, número de volumes e números publicados no período de 2000 a 2010, quantidade de artigos publicados em cada um desses volumes/números, quantidade de artigos selecionados, além de outras informações complementares e pertinentes ao processo de pesquisa, tais como o principal foco de atenção, se apresentou períodos em que não houve publicações, entre outros.

Desse modo, concluída essa primeira etapa de seleção de dados, verificamos que os 95 periódicos destacados disponibilizaram um total de 15.828 artigos no período de 2000 a julho de 2010. Após a análise de seus conteúdos e verificação de seu enquadramento em nossa pesquisa, reduzimos para 135 artigos.

Por meio de leituras e releituras dos 135 artigos, verificamos que 37 deles focavam, de forma especial e direta, a intersecção que buscávamos: a Educação Matemática na EJA. Os demais apresentavam análises complementares sobre temas relativos à EJA, mas que consideramos como imprescindíveis à nossa pesquisa. Diante dessas percepções, separamos os 135 artigos em dois grupos: 
- Grupo 1: com 37 artigos que tratam diretamente do tema de nossa pesquisa: A Educação Matemática na EJA;

- Grupo 2: com 98 artigos que consideramos tratar de forma indireta o tema de nossa pesquisa, ou que, por focarem a EJA, foram utilizados como complementares em nossas análises.

Como objetivo de verificarmos a qualidade e a abrangência de nossas opções metodológicas até este ponto, elaboramos uma nova pesquisa/consulta ao Banco de Teses da CAPES. Dessa vez, buscando conhecer quantas e quais foram as pesquisas de doutorado produzidas no Brasil no período de 2000 a 2010 que tenham envolvido nosso tema de análise. Para isso, utilizamos como critério de consulta a simples ocorrência (no título, nas palavras-chave ou no resumo) das expressões de busca: "Educação matemática", "Educação matemática na EJA", "numeramento na EJA", "Educação matemática de jovens e adultos" e "EJA".

Após um longo processo de verificação de quais produções realmente se adequariam à nossa pesquisa, e de efetuar o descarte das informações duplicadas, chegamos, finalmente, à seleção de 12 teses defendidas no período destacado, envolvendo temas relacionados, de alguma forma, à Educação e Educação Matemática na EJA, e que poderiam pertencer a um dos Grupos de nossa análise (1 ou 2). Ao cruzarmos as informações dessas teses com os nossos registros dos 135 artigos selecionados dos periódicos, tivemos a grata surpresa de verificar que, do total de 12 teses encontradas, 8 tinham originado artigos que constavam de nossa seleção.

No intuito de ampliarmos um pouco mais essa verificação de qualidade e abrangência de nossas escolhas metodológicas, passamos a analisar os temas de pesquisa de mestrado e/ou doutorado dos professores componentes do Grupo de Trabalho de Educação Matemática da Associação Nacional de Pós-Graduação e Pesquisa em Educação (ANPED), GT 19, e, caso verificássemos que se direcionassem para a Educação Matemática na EJA, buscaríamos saber se geraram artigos pertencentes à nossa seleção.

Encontramos na página da ANPED, na subpágina referente aos participantes do GT 19 da $34^{\circ}$ reunião anual da entidade, ocorrida na cidade de Natal (RN) em outubro de 2011, um total de 43 nomes de professores pesquisadores. Passamos a pesquisar a produção desses participantes no Banco de Teses da CAPES, e obtivemos êxito em 32 dos casos. Após a leitura dos títulos, palavras-chave e resumos, verificamos que tínhamos encontrado uma ampla variedade de temas de pesquisas (Educação Infantil, formação de professores, avaliação, currículo etc.), porém, nenhuma direcionada ao nosso foco de estudo.

Por isso, a partir dessa constatação, decidimos redirecionar nossa pesquisa para o Grupo de Trabalho da ANPED de Educação de Pessoas Jovens e Adultas (GT 18). Após analisarmos diversas informações, verificamos a não-disponibilidade dos nomes dos participantes do Grupo, mas conseguimos levantar alguns dos participantes das atividades ocorridas em 2011 na reunião anual da entidade. Dessa lista, optamos por elencar os nomes dos: professores coordenadores, participantes do comitê científico, debatedores e apresentadores de minicursos. Assim, chegamos ao total de 12 professores pesquisadores. Por fim, comparamos esses nomes com os autores de artigos selecionados em nossa pesquisa, e verificamos que 11 deles tinham desenvolvido trabalhos que pertenciam à nossa lista de artigos selecionados para o nosso estudo.

Embora reconheçamos que essas verificações possuam pontos frágeis, elas nos serviram para a compreensão de que o nosso Estado da Arte possuía a característica de envolver os estudos em nosso tema da EJA de uma forma ampla, mesmo que, para isso, tivéssemos de abrigar produções provenientes de outras áreas do conhecimento, exteriores à Educação Matemática. 
Essas verificações ainda nos servem para alertar sobre a falta de participação de professores/pesquisadores da Educação Matemática que tenham, como foco de suas pesquisas, a EJA nas reuniões do GT 19 - o que pode desencadear certo distanciamento ainda maior de tal tema das atenções das comunidades de pesquisa. Em contrapartida, verificamos, também, que o Grupo de Trabalho que possui foco específico em EJA tem produzido e propagado diversos estudos (envolvendo, inclusive, a Educação Matemática).

Um dos entendimentos decorrentes de todo esse processo foi o de que a abrangência de produções de outras áreas além da matemática, em nosso estudo, possibilitaria de fato uma multiplicidade de perspectivas e pluralidades de enfoques sobre o tema; e que o olhar desses diversos autores/pesquisadores selecionados nos proporcionaria as articulações de importantes análises, o diálogo interdisciplinar com o objetivo de integrarmos, dentre outros pontos estruturais de estudo: os resultados dessas pesquisas, as incoerências, os pontos de tensão, os pontos compatíveis e as recomendações possíveis.

Dando prosseguimento à nossa descrição do processo metodológico, relatamos que, após leituras atentas dos resumos e das palavras-chave dos artigos selecionados nos dois Grupos, optamos por separar os artigos por temas de análise (HADDAD, 2000). Em um processo longo de releituras e classificações, chegamos aos quatro temas que compuseram nossa análise. Desta forma, optamos por desmembrar a nossa questão inicial de pesquisa em quatro partes distintas, porém complementares:

a) O que tem sido produzido e publicado sobre o tema Formação/Atuação do Professor/Alfabetização da EJA?

b) O que tem sido produzido e publicado sobre o tema Práticas Pedagógicas na EJA?

c) O que tem sido produzido e publicado sobre o tema Currículo da EJA?

d) O que tem sido produzido e publicado sobre o tema Avaliação da/na EJA?

Essas questões representaram a configuração dos quatro temas que emergiram desse processo de coleta e organização de dados:

i) Formação/Atuação do Professor/Alfabetizador da EJA;

ii) Práticas Pedagógicas na EJA;

iii) Currículo da EJA, e

iv) Avaliação da/na EJA.

Consideramos que essa configuração final com os quatro temas relatados acima seja o resultado de um amadurecimento das reflexões provenientes das leituras dos artigos. Esse processo de busca pela compreensão da mensagem das produções culminou na percepção de que não haveria a necessidade de ampliarmos em demasia a quantidade de temas, e que, nesse formato, as diferentes vertentes desses temas que emergissem das leituras poderiam ser contempladas em nossa pesquisa.

A estrutura organizacional que apresentamos é oriunda, também, do entendimento da impossibilidade de delimitação clara de abrangência entre os próprios temas, mas, tanto na teoria quanto na prática educacional, eles se complementam, se tocam e, por vezes, se mesclam. Nessa concepção, compreendemos que a própria estrutura polissêmica dos temas poderia reivindicar espaços de diálogos entre eles e outros que se apresentariam implícita ou explicitamente, apresentando sua aproximação e distanciamentos, seus pontos de influência, lacunas e pontos que representam suas singularidades. Afinal, todos se relacionam à educação, assunto rico em possibilidades de análises e interpretações, e todas elas diretamente relacionadas aos 
nossos entendimentos, experiências, vivências e leituras da contemporaneidade e das pessoas que a compõem, e da qual fazemos parte.

\section{A opção pela Análise Textual Discursiva}

A pesquisa qualitativa envolvendo os 135 artigos selecionados passou, em seguida, à fase do que denominamos de metatexto, para a construção do Estado da Arte da Educação Matemática na EJA. Para tanto, desenvolvemos uma proposta, que consideramos inovadora, de utilização da Análise Textual Discursiva em conjunto com a elaboração de Mapas Conceituais, como forma de melhor compreensão e descrição/interpretação das leituras e análises.

Destacamos que o nosso entendimento de leitura se baseou nos estudos de Chartier (1998, 2009), para quem a leitura é sempre uma prática criadora, inventiva e produtora, e que, portanto, as significações dos textos, quaisquer que sejam, serão constituídas, pelo leitor/analista, diferencialmente pelas leituras que se apoderam desses textos. O ato de ler dá, ao texto lido, significações plurais e móveis, situadas no encontro das diversas formas de ler (coletivas ou individuais, herdadas ou inovadoras, íntimas ou públicas) e dos "protocolos de leitura depositados no objeto lido" (CHARTIER, 2009, p. 78) pelo autor que busca indicar a compreensão de seu texto; e, também, pelo impressor que compõe as formas tipográficas em conformidade com os hábitos de seu tempo. Chartier destaca que não devemos nos esquecer de que o texto produzido não muda enquanto o mundo muda, o que significará a própria mudança do texto por meio de sua leitura, pois os espaços dos livros em que serão lidos já estarão diferentes.

A opção pela Análise Textual Discursiva (ATD) deveu-se ao fato de suas características propiciarem uma pesquisa qualitativa envolvendo análises criteriosas de textos diversos, e, a partir daí, uma melhor compreensão dos fenômenos investigados, para, em seguida, culminarem no desenvolvimento de um metatexto que seja representativo desse movimento. Tomamos como base os estudos de Moraes e Galiazzi (2006, 2011), que caracterizam a ATD como uma metodologia na qual, a partir de um conjunto de textos, é possível construir um metatexto que descreva e interprete os sentidos e significados que o pesquisador/analista compreenda a partir do corpus desse material.

O primeiro passo do ciclo de ATD é tido como um momento de intenso contato e impregnação com o material de análise, envolvendo leituras desse material tendo por base o entendimento de que os textos não carregam um significado único a ser identificado; trazem significantes que exigem que o analista construa significados a partir de suas teorias, seu foco de pesquisa e pontos de vista. Nesse ponto, a ATD promove uma fragmentação dos textos no sentido de se atingirem as suas unidades constituintes e enunciados referentes aos fenômenos estudados. É o processo de desmontagem ou "unitarização" dos textos.

É um processo de constante desestabilização e reestruturação da ordem a partir da desordem promovida pela unitarização, pois "o estabelecimento de novas relações entre os elementos unitários de base possibilita a construção de uma nova ordem” (MORAES; GALIAZZI, 2011, p. 21), o que significa novas compreensões em relação aos fenômenos investigados.

Com base nesse processo de impregnação das informações dos textos, passa-se ao segundo momento da ATD, que é a busca pelo estabelecimento de relações/comparações entre as unidades definidas no passo anterior, levando ao agrupamento de elementos semelhantes: 
a "categorização" (MORAES, 2003). Entendemos ser um processo de comparação constante entre as unidades definidas no processo de análise, levando a agrupamentos de elementos semelhantes. Entretanto, embora apresentem unidades conceituais homogêneas, esses conjuntos podem se apresentar de forma que sejam analisados como complementares, ou seja, a análise sobre as características gerais e amplas de cada complexidade dos conceitos envolvidos pode promover ligações entre essas categorias selecionadas.

A partir do processo de fragmentação, unitarização e categorização do corpus, passamos à etapa da construção do "metatexto descritivo-interpretativo" (OLIVEIRA; RECENA, 2009), que pretendeu promover interlocuções empíricas ancoradas em argumentos e informações extraídas dos textos. Para Moraes (2003) e Moraes e Galiazzi (2006, 2011), na ATD, os metatextos não devem ser entendidos simplesmente como forma de apresentar algo já expresso nos textos, mas como construções do pesquisador/analista com intenso envolvimento de sua parte, em que as descrições/interpretações e teorizações apresentadas como resultados de suas análises constituem resultado de um esforço de construção intensa e rigorosa.

Durante o desenvolvimento do processo cíclico de reconstrução de conhecimentos de nossa pesquisa, resolvemos tomar, como ponto de partida, a elaboração de Mapas Conceituais (MOREIRA, 1988), como forma de analisar os conceitos, discursos e conhecimentos já estabelecidos nos textos, e promover relações entre as ideias explícitas e implícitas colhidas durante as leituras e releituras deles.

Pelo que conseguimos apurar a respeito de pesquisas anteriores que se utilizaram da ATD, nossa metodologia apresenta uma combinação original de ferramentas que busca a organização sistematizada do conhecimento, e facilita o enlace de ideias e conceitos, enunciados isolados sobre o tema, e a correlação entre os diversos pensamentos elencados nos textos.

Em um processo bastante denso e demorado, optamos pela elaboração de Mapas Conceituais como forma de proporcionar uma melhor emergência dos conhecimentos provenientes das leituras dos textos. Para esse processo de impregnação e apropriação das ideias e conceitos apresentados nas produções, optamos pela elaboração de um Mapa Conceitual para cada um dos artigos selecionados ${ }^{8}$. Posteriormente, elaboramos Mapas Conceituais gerais, aglutinadores de conhecimentos, sobre cada um dos temas de estudo ("Formação/Atuação do Professor/ Alfabetizador da EJA", "Práticas Pedagógicas na EJA", "Currículo da EJA" e "Avaliação da/na EJA"), de tal forma que as principais ideias de cada uma das produções destacadas nos temas pudessem ser destacadas, e, quando possível, relacionadas às ideias dos outros artigos, gerando um melhor entendimento das produções em conjunto. Nesse mosaico, buscamos apresentar possíveis elos entre as produções, assim como pontos de tensão e discordância.

\section{Algumas informações coletadas}

Para darmos amostras de alguns dos dados coletados em nosso Estado da Arte, relataremos, nesta última seção, um breve resumo a respeito das considerações gerais sobre os

\footnotetext{
${ }^{8}$ Para o desenvolvimento dessa atividade, utilizamos o software CMAP TOOLS, elaborado pelo Institute for Human and Machine Cognition (IHMC). Disponível em: <http://www.ihmc.us/about.php>. Acesso em: 11 fev. 2012.
} 
135 artigos selecionados, visto que o espaço reduzido não nos permitiria analisarmos os dados específicos dos temas destacados. Mas, podemos salientar, dentre outras percepções, a de que as pesquisas em Educação Matemática na EJA ainda possuem um longo caminho a ser trilhado: o de aprofundar os conhecimentos a respeito das possíveis contribuições dessa área sobre a vida cultural/social dos aprendentes e as melhores formas de fazê-lo.

A quase totalidade das pesquisas foi classificada pelos próprios autores como qualitativa, mas, por diversas vezes, verificamos a recorrência também a dados quantitativos provenientes de outras pesquisas, como suporte para justificativas relacionadas aos temas de análise. Uma quantidade considerável de produções apresentou-se como relatos de experiência, e as produções que apresentaram descrições sobre a metodologia adotada na pesquisa citaram, dentre outras: análises de documentos e de outras obras diversas, análise de entrevistas, análise de respostas a questionários, análises de videogravações, elaboração de grupo de estudo e debate, implementação de oficinas de trabalhos pedagógicos, análise observacional participativa e/ou exploratória de atividades (desenvolvidas por alunos, professores, coordenadores etc.), análise de registros de pesquisa de campo, análises de portfólios, e análises etnográficas.

Uma grande quantidade das produções fez uso de apresentação de episódios da história da EJA no Brasil e em outros países, na intenção de proporcionar, ao leitor, uma introdução, ou aprofundamento, aos temas em análise, e, dessa forma, inteirá-lo de quais foram as possíveis conjecturas sociais, políticas e culturais que determinaram os quadros atuais em educação direcionada a jovens e adultos.

Com relação aos referenciais teóricos utilizados nas pesquisas, destacamos a ocorrência de um vasto e, algumas vezes, disperso universo de ideias e diálogos promovidos entre autores das mais diferentes áreas: educação matemática, educação, psicologia, filosofia, sociologia etc. Entretanto, destacou-se a grande recorrência aos estudos desenvolvidos pelos educadores Paulo Freire e Ubiratam D’Ambrosio.

Verificamos que cerca de $80 \%$ dos autores/pesquisadores das produções analisadas (179 de um total de 226) eram do sexo feminino. Estes dados nos mostram que a quase totalidade dessas pesquisas foi elaborada/coordenada por mulheres. No entanto, ressalta-se que tal característica não se refletiu em ampla discussão sobre a questão gênero nos artigos.

Tendo por base as instituições das quais os autores/pesquisadores apresentaram indicações do local onde a pesquisa teria sido desenvolvida, contabilizamos que, do total de autores/pesquisadores: cerca de 92\% (208) estavam ligados a instituições de nível Superior e/ ou pós-graduação, 8 ligados a instituições de nível Fundamental e/ou Médio, 7 a ONG, e 3 não apresentaram essa informação.

Sobre a distribuição geográfica dessas instituições, destacamos a ocorrência de autores/ pesquisadores que indicaram ligação com universidades situadas fora do Brasil (Argentina, Chile, Espanha, EUA, Hungria, México, Portugal e Romênia). Ao analisarmos os que indicaram ligação com instituições brasileiras, verificamos acentuado destaque para as das regiões Sudeste e Sul do Brasil, com predominância significativa de pesquisas provenientes de instituições públicas.

Em nossas análises, verificamos que existem ainda preconceitos que permeiam a formação/atuação do professor na EJA, tais como a desvalorização sobre o trabalho desse profissional, devido, muitas vezes, ao fato de lidarem diretamente com alunos desfavorecidos. Há, ainda, a percepção de que pela EJA ser bastante marcada pela filantropia, ou por docentes leigos, leva ao entendimento errôneo de que essa é uma escolarização/atuação menor, que 
poderia ser simplificada, e o profissional que nela atua não precisaria de formação específica. Consideramos que tais preconceitos podem ser causa e, às vezes também, efeito dos poucos espaços ofertados aos cursos de formação dessa área.

Diversas produções apresentaram ampla defesa de uma formação que leve o professor de matemática, e de outras áreas, a encarar, como sua tarefa primordial, a construção da cidadania de seu alunado. Entretanto, analisamos, tão importante quanto essa percepção da função do educador da EJA, é a de que não pode ser negado a esse aluno o acesso aos códigos, símbolos e operações matemáticas, assim como a outros conhecimentos básicos. O que não deve significar uma educação cuja utilidade seja a de apenas certificar ou preparar o aluno para o trabalho, mas, sim, uma conquista de direitos, inclusive, ao conhecimento.

\section{Referências}

ANDRÉ, M. E. D. A. (Org.). Formação de professores no Brasil (1990-1998). Brasília: MEC: INEP: COMPED, 2002. Disponível em: <https://www.faneesp.edu.br/site/ documentos/serie_estado_conhecimento2.pdf >. Acesso em: 13 maio 2015.

ANDRÉ, M. et al. Estado da arte da formação de professores no Brasil. Educação \& Sociedade, Campinas, v. 20, n. 69, p. 301-309, 1999. Disponível em: <http://www.scielo.br/ pdf/es/v20n68/a15v2068.pdf >. Acesso em: 13 maio 2015.

BOGDAN, R.; BIKLEN, S. Investigação qualitativa em educação: uma introdução à teoria e aos métodos. Porto: Porto Editora, 1991.

CARVALHO, R. V. O estado da arte das pesquisas em educação de jovens e adultos na Capes: período de 1987- 2006. Cadernos de Pesquisa: Pensamento Educacional, Curitiba , v. 4, n. 8, p. 117-130, 2009. Disponível em: < http://universidadetuiuti.utp.br/Cadernos_de_ Pesquisa/pdfs/cad_pesq8/7_estado_arte_cp8.pdf>. Acesso em: 13 maio 2015.

CHARTIER, R. A aventura do livro: do leitor ao navegador. São Paulo: Ed. Unesp, 1998.

. Práticas da leitura. São Paulo: Estação Liberdade. 2009.

CRESWELL, J. W. Projeto de pesquisa: métodos qualitativo, quantitativo e misto. 2. ed. Porto Alegre: Artmed, 2007.

D’AMBROSIO, U. Educação matemática: uma visão do estado da arte. Pro-posições, Campinas, v. 4, n. 1, p. 7-17, 1993. Disponível em: <http://www.proposicoes.fe.unicamp.br/ proposicoes/textos/10-artigos-d\%5c'ambrosiou.pdf>. Acesso em: 05 nov. 2012.

FERREIRA, N. S. A. As pesquisas denominadas “estado da arte”. Educação \& Sociedade, Campinas, v. 23, n. 79, 2002. Disponível em: <http://www.scielo.br/pdf/es/v23n79/10857. pdf>. Acesso em 29 abr. 2012.

GARCIA, T. C. M. Trabalho docente, formação e profissionalização: o que nos revela o cotidiano do professor. 2005225 f. Tese (Doutorado) - Universidade Federal do Ceará, Fortaleza, 2005. 
GIL, A. C. Métodos e técnicas de pesquisa social. 6. ed. São Paulo: Atlas, 2008.

HADDAD, S. O estado da arte das pesquisas em educação de jovens e adultos no

Brasil: a produção discente da pós-graduação em educação no período 1986-1998. São Paulo: Ação Educativa, 2000.

. Juventude e escolarização: uma análise da produção de conhecimentos. Brasília: MEC: INEP, 2002.

LARANJEIRA, R. Estado da arte do direito agrário no Brasil. In: SEMINÁRIO NACIONAL DE DIREITO AGRÁRIO, 11., 2003, São Luís. Anais... Disponível em: <http://abda.com.br/texto/RaymundoLaranjeira.pdf>. Acesso em: 18 maio 2015.

LITTOO, F. M.; FORMIGA, M. Educação a distância: o estado da arte. São Paulo: Pearson, 2009.

LUNA, S. V. Planejamento de pesquisa: uma introdução. São Paulo: EDUC, 2007.

MELO, M. V. Três décadas de pesquisa em educação matemática: um estudo histórico a partir de teses e dissertações. 2006. 273 f. Dissertação (Mestrado) - Faculdade de Educação, Universidade Estadual de Campinas, Campinas, 2006.

MORAES, R. Uma tempestade de luz: a compreensão possibilitada pela análise textual discursiva. Ciência \& Educação, Bauru, v. 9, n. 2, p. 191-211, 2003. Disponível em: <http://www.scielo.br/pdf/ciedu/v9n2/04.pdf>. Acesso em: 20 fev. 2012.

MORAES, R.; GALIAZZI, M. C. Análise textual discursiva: processo reconstrutivo de múltiplas faces. Ciência \& Educação, Bauru, v. 12, n. 1, p.117-128, 2006. Disponível em: < http://www.scielo.br/pdf/ciedu/v12n1/08.pdf>. Acesso em: 20 fev. 2012.

Análise textual discursiva. 2. ed. Ijuí: Ed. Unijuí, 2011.

MOREIRA, M. A. Mapas conceituais e aprendizagem significativa. O Ensino: revista galáico portuguesa de sócio-pedagogia e sócio-linguística, Pontevedra, n. 23, p. 87-95, 1988. Disponível em: < http://www.if.ufrgs.br/ moreira/mapasport.pdf>. Acesso em: 20 fev. 2012.

MOROSINI, M. C. Educação superior em periódicos nacionais (1968-1995). Brasília: MEC: Inep: Comped, 2001.

OLIVEIRA, A. M.; RECENA, M. C. P. A investigação temática e a análise textual discursiva: busca por temas geradores. In: ENCONTRO NACIONAL DE PESQUISA EM EDUCAÇÃO EM CIÊNCIAS, 7., 2009, Florianópolis. Anais... Rio de Janeiro: ENPEC, 2009. Disponível em: < http://posgrad.fae.ufmg.br/posgrad/viienpec/pdfs/1100.pdf >. Acesso em: 20 fev. 2012.

ROCHA, M. A.; SALVI, R. F. Panorama atual sobre os trabalhos de campo em periódicos da área de ensino de ciências (2005-2009). In: ENCONTRO DE GEÓGRAFOS BRASILEIROS, 16., 2010, Porto Alegre. Anais... Porto Alegre, 2010. p. 1-10.

ROMANOWSKI, J. P.; ENS, R.T. As pesquisas denominadas do tipo “estado da arte” em educação. Diálogo Educacional, Curitiba, v. 6, n. 19, p. 37-50, 2006. 
Freitas, A. V.; Pires, C. M. C.

SLONGO, I. I. P. A produção acadêmica em ensino de biologia: um estudo a partir de teses e dissertações. Florianópolis: UFSC, 2004.

SOARES, M. B.; MACIEL, F. Alfabetização. Brasília: MEC: Inep, 2000.

SPOSITO, M. P. Juventude e escolarização (1980-1998). Brasília: MEC: Inep: Comped, 2002.

TEIXEIRA, C. R. O “estado da arte”: a concepção de avaliação educacional veiculada na produção acadêmica do programa de pós-graduação em educação: currículo (1975- 2000).

Cadernos de Pós-Graduação: educação, São Paulo, v. 5, n. 1, p. 59-66, 2006.

TEIXEIRA, P. M. M. Pesquisa em ensino de biologia no Brasil (1972-2004): um estudo baseado em dissertações e teses. 2008. 413 f. Tese (Doutorado em Educação) - Faculdade de Educação, Universidade Estadual de Campinas, Campinas, 2008.

ULER, A. M. Avaliação da aprendizagem: um estudo sobre a produção acadêmica dos programas de pós-graduação em educação (PUCSP, USP, UNICAMP). 2010. Tese

(Doutorado em Educação) - Pontifícia Universidade Católica de São Paulo, São Paulo, 2010.

VERMELHO, S. C.; ABREU, G. I. P. O estado da arte da área de educação \& comunicação em periódicos brasileiros. Educação \& Sociedade, Campinas, v. 26, n. 93, p. 1413-1434, 2005.

WITTMANN, L. C.; GRACINDO, R. V. Políticas e gestão da educação (1991-1997).

Brasília: MEC: Inep: Comped, 2001.

Artigo recebido em 24/04/14. Aceito em 03/03/15. 